\title{
REPEATABILITY OF TEMPERAMENT SCORES IN BUNAJI AND FRIESIAN-BUNAJI CROSSES
}

\author{
B. Y. ABUBAKAR, O. O. ONI, S. A. S. OLORUNJU \\ and V. BUVANENDRAN \\ National Animal Production Research Institute \\ Ahmadu Bello University, P.M.B. 1096, \\ Shika, Zaria, Nigeria. \\ Received 3 September, 1992 Accepted 30 Decembcr, 1992
}

\begin{abstract}
Repeatabilities of temperament scores were estimated by breed, sex, age, weight and body condition in an enclosed weighbridge (method 1) and in a cattle crush (method 2). The model used included animal, scorer, animal $x$ scorer and replicate within scorer effects. The within and between animal variation accounted for 44 and 54\%, respectively, for method 1 and 67 and $32 \%$, respectively, of total variation for method 2. Animal $x$ scorer interaction was not significant. For both methods, repeatabilities for temperament scores were 0.56 and 0.54 , for method 1 and 0.33 and 0.32 , for method 2. Scoring animals in seclusion seems to enhance expression of temperament and hence is more repeatable and reproducible.
\end{abstract}

Key words: Bunaji; Friesian-Bunaji cattle; Temperament scores; Repeatability.

\section{INTRODUCTION}

Temperament scoring can be used as an effective management tool on cattle farms, just as body condition is used. Cattle with nervous temperaments pose serious management problems (Elder et al. 1980), but have reccived little attention from a research point of view. Any scoring system for temperament should reflect difficulties experienced by stockmen, when handling animals in a crush, pens or other confinements. Such methods

Vigerian Journal of Animal Prod. 20 (1993) must be repeatable to instil confidence in culling procedures. Temperament has been measured by an increase in heart rate (Czako 1979), and production of lactic acid in the blood (Holmes et al. 1972); other researchers (Hearnshaw and Morris 1984; Fordyce et al. 1985) have classified cattle into behavioural categories such as docile, restless or aggressive. Hearnshaw et al. (1979) used a modified temperament score described by Tulloh (1961) and reported that animals from crosses involving Bos indicus were more difficult to handle in a crush than pure or crossbred Bos taurus animals. Also breed, sex, season, liveweight, and body condition have been found to have significant effect on temperament (Abubakar et al. 1991). The present study was designed to compare temperament scoring in a cattle crush and in an enclosed weighbridge using repeatabilities estimated from variance components.

\section{MATERIALS AND METHODS}

The animals used in this study were part of the experimental herd of the National Animal Production Research Institute, Shika, in the Northern Guinea Savannah zone of Nigeria. The 175 animals used were either purebred Bunaji or $50 \%$ Friesian $x$ Bunaji crosses and the latter were either progeny from purebred Bunaji or $50 \%$ Fricsian $x$ Bunaji crossbred dams. Both males and females of various ages were used. However, pregnant animals were excluded from the study. Location and management of animals have been described by Buvanendran et al. (1981). 


\section{Experimental Procedures}

Temperament of each animal was scored simultaneously by two scorers (B.Y.A. and O.O.O) for $2 \mathrm{~min}$ in a weighbridge (method 1 ) and in a cattle crush (method 2). The weighbridge consists of an Avery weighing scale $(2.2 \times 1.5 \mathrm{~m})$ that can weigh up to 500 $\mathrm{kg}$. The weighing area is enclosed by horizontal bars at the sides with crossing vertical bars at $0.4 \mathrm{~m}$ apart. The inlet and outlet are controlled by doors on railings so that animals could enter the weighing area singly. The whole scale is housed in an open sided building. The crush is built of concrete and is $20.4 \mathrm{~m}$ long, $0.5 \mathrm{~m}$ wide with a depth of $0.7 \mathrm{~m}$. On each side are two horizontal bars with crossing vertical bars $(0.5 \mathrm{~m}$ high) that are $1.2 \mathrm{~m}$ apart. There are holding yards at both ends of the crush and also two doors controlling the inlet and outlet.

Except for some practice to familiarize themselves with the technique of scoring prior to the study, the two scorers had no previous experience. Vigour of movement was scored on a six-point scale as follows: 1 , no movement; 2 , slightly restless with minor movement; 3, almost continuous but non-vigorous movement; 4, quite vigorous movement; 5, very disturbed and continuous vigorous movement; 6 , struggling violently and attempting to jump out.

Audible respiration was scored on four levels (Fordyce et al. 1985); O, no audible respiration; 0.5 , heavy breathing; 1 , very heavy breathing; 1.5 , sncrting.

Other behavioural features scorcd were whether an animal knelt or laid down, bellowed or kicked. As each of these behaviours was infrequent, their scoring was done collectively. Bellowing or kicking were scored as 1 if they occurred and 0 if they did not. An animal that bellowed and kicked still received a score of 1 . A score of 2 was given for lying down. Therefore in this behavioral catcgory the maximum score for an animal was 2. For cach animal, scores for all behaviours were added to form the temperament score'.
Each of the scores were replicated once within a period of 24 hours. Animals were not necessarily presented in the same order each time. Body condition was scored by the same two scorers following the technique outlined by Pullan (1978). The scoring was on a six-point scale as follows; 1, marked emaciation with individual lumbar processes projecting prominently and neural spines appearing sharply; 2 , hips, pins, tail-head and ribs prominent; 3 , ribs visible, little fat cover and spinous processes barely visible; 4, animal smooth and well covered with spinous processes that cannot be seen but easily felt; 5, fat cover in critical areas and lumbar processes cannot be seen or felt: 6, heavy deposit of fat clearly visible on tail-head, brisket and cod.

\section{Statistical Analysis}

A trial in which animals are individually scored once is not very satisfactory because animal scorer interactions are confounded. Replication allows the effects to be separated in an analysis of variance. The model used in this study was as follows:

Yijk $=\mu+a_{i}+s_{j}+(a s)_{i j}+r_{k}(j)+e_{i j k}$ where

$Y_{i j k}$ is temperament score for animal $i$, scorer $\mathrm{j}$ and replicate $\mathrm{k}$;

$\mu$ is overall mean;

$\mathrm{a}_{\mathrm{i}}$ is random effect of the $\mathrm{i}^{\mathrm{th}}$ animal, $\mathrm{i}=1, \ldots, \mathrm{n}$;

$s_{j}$ is random effect of the $j^{\text {th }}$ scorer

$$
\mathrm{j}=1, \ldots, \mathrm{m} \text {; }
$$

$(\mathrm{as})_{\mathrm{ij}}$ is animal $\mathrm{x}$ scorer interaction effect;

$r_{k(i)}$ is replicate within scorer effect;

$$
\mathrm{k}=1, \ldots, \mathrm{p} \text {; and }
$$

$\mathrm{e}_{\mathrm{ijk}}$ is random error term

The model assumes that successive scorings by a particular scorer are independent, and that the scorers assess each animal independently. The analysis was carried out within breed group, sex, age, weight and body condition. An overall analysis was also done irrespective of the above variables. In the ANOVA table for this model, if the components of variance 


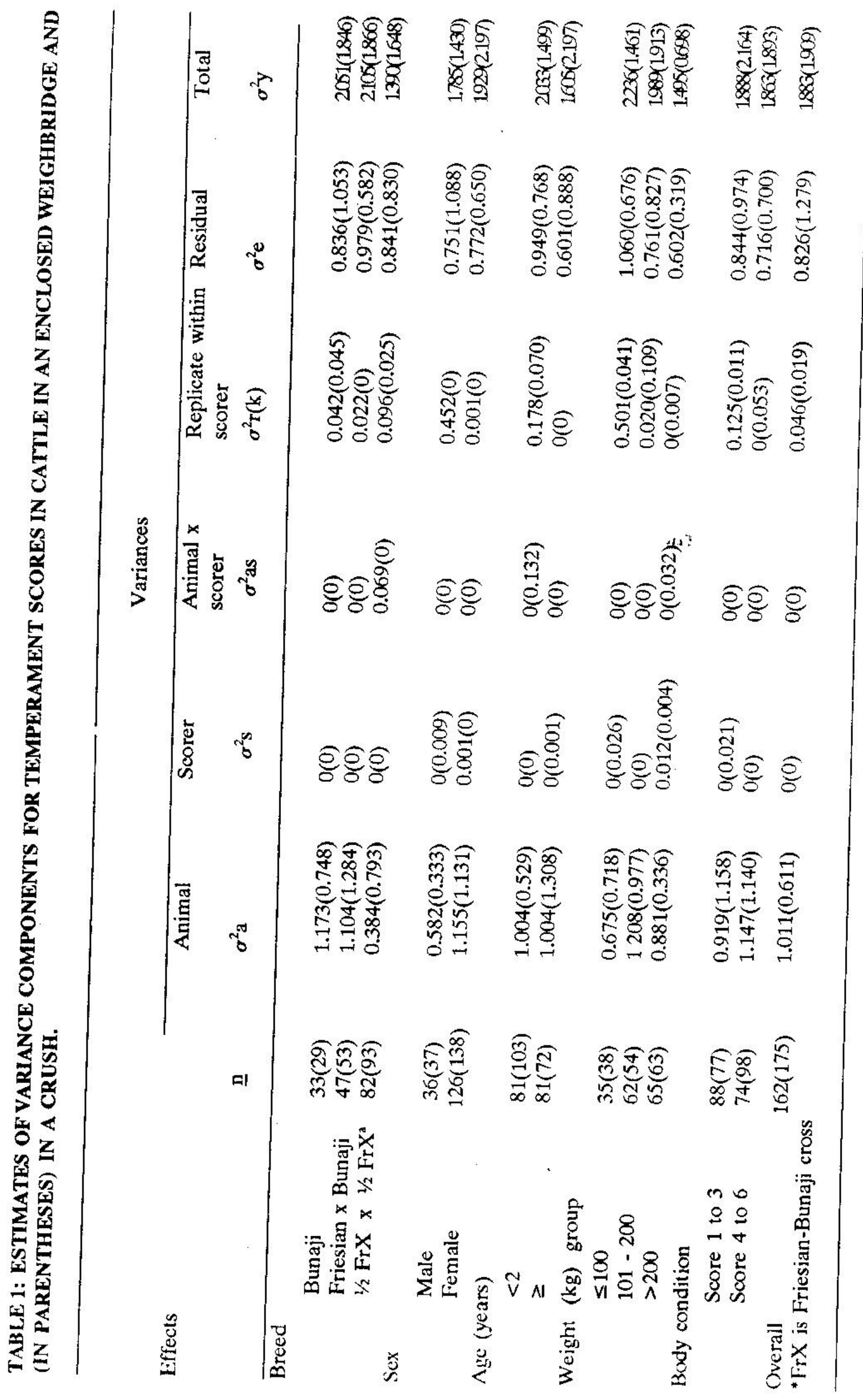


TABLE 2: REPEATABILITIES WITHIN (r1) AND BETWEEN (r2) SCORERS FOR TEMPERAMENT SCORES OF CATTLE IN AN ENCLOSED WEIGHBRIDGE AND IN A CRUSH.

\begin{tabular}{lllllll}
\hline & \multicolumn{3}{c}{ Weighbridge } & & Crush & \\
Effects & $\mathrm{r} 1$ & $\mathrm{r} 2$ & $\mathrm{r} 1$ & & $\mathrm{r} 2$ \\
\hline
\end{tabular}

Breed

$\begin{array}{lllll}\text { Bunaji } & 0.59 & 0.57 & 0.43 & 0.41 \\ \text { Friesian x Bunaji } & 0.54 & 0.52 & 0.69 & 0.69 \\ 1 / 2 \text { FrX X } 1 / 2 \text { FrX } & 0.39 & 0.28 & 0.50 & 0.48\end{array}$

Sex

$\begin{array}{lllll}\text { Male } & 0.58 & 0.33 & 0.24 & 0.23 \\ \text { Female } & 0.60 & 0.60 & 0.64 & 0.64\end{array}$

Age (years)

$\begin{array}{lllll}<2 & 0.53 & 0.45 & 0.49 & 0.35 \\ \geq 2 & 0.63 & 0.63 & 0.60 & 0.60\end{array}$

Weight (kg)

$\begin{array}{lllll}\leq 100 & 0.53 & 0.30 & 0.54 & 0.49 \\ 101-200 & 0.62 & 0.61 & 0.57 & 0.51 \\ >200 & 0.60 & 0.59 & 0.54 & 0.48\end{array}$

Body condition

$\begin{array}{lllll}\text { Score } 1 \text { to } 3 & 0.55 & 0.48 & 0.55 & 0.54 \\ \text { Score } 4 \text { to } 6 & 0.62 & 0.62 & 0.63 & 0.60\end{array}$

Overall

0.56

$0.54 \quad 0.33$

0.32

${ }^{\text {a }} \mathrm{FrX}$ is Friesian-Bunaji cross

due to animals, scorers, animals $x$ scorers, replicate within scorers and residuals are respectively- $\sigma^{2} \mathrm{a}, \sigma^{2} \mathrm{~s}, \sigma^{2} \mathrm{as}, \sigma^{2} \mathrm{r}(\mathrm{s}), \sigma^{2} \mathrm{e}$, the expected mean squares are:
Effect
Animals
Scorers
Expected mean squares $\sigma^{2} \mathrm{e}+\mathrm{p} \sigma^{2} \mathrm{as}+\mathrm{mp} \sigma^{2} \mathrm{a}$ $\sigma^{2} \mathrm{e}+\mathrm{n} \sigma^{2} \mathrm{r}(\mathrm{s})+\mathrm{p} \sigma^{2} \mathrm{as}+\mathrm{np} \sigma^{2}$

Animals x scorers $\quad \sigma^{2} \mathrm{e}+\mathrm{p} \sigma^{2}$ as

Replicates/scorers $\quad \sigma^{2} \mathrm{e}+\mathrm{n} \sigma^{2} \mathrm{r}(\mathrm{s})$

Residuals $\quad \sigma^{2} \mathrm{e}$

These types of model have been discussed by Henderson (1959). Estimates of the variance components were used to give the following intra-class correlations: 


$$
r_{1}=\frac{\sigma^{2} y-\sigma^{2} e}{\sigma^{2} y} \quad r_{2}=\begin{array}{r}
\sigma^{2} \mathrm{a} \\
\hdashline-\sigma^{2} \mathrm{y}
\end{array}
$$

where

$r_{1} \quad$ is repeatability of scores within scorers,

$r_{2}$ is repeatability of scores between scorers, and

$\sigma^{2} \mathrm{y} \quad$ is $\sigma^{2} \mathrm{a}+\sigma^{2} \mathrm{~s}+\sigma^{2} \mathrm{as}+\sigma^{2} \mathrm{r}(\mathrm{s})+\sigma^{2} \mathrm{e}$

In cases where negative variance component estimates resulted, they were replaced by zeros, and other components were recalculated, following Searle (1971).

\section{RESULTS}

Estimates of variance components are shown in Table 1. Replicate effects were included to allow for the possibility that some scorers may revise their scores upward or downward on the second scoring. Animal $\mathrm{x}$ replicate effects were not included as the replicated scorings were made within $24 \mathrm{~h}$. Most of the variation was attributable to between and within animal components. Scorers and animal $\mathrm{x}$ scorer variations were negligible, and the replicate within-scorer variance accounted for $<2 \%$ of the total variation. The between-animal variation was generally higher for scores taken in the weighbridge than for those taken in the crush. Repeatabilities within and between scorers were estimated from the variance components (Table 2). The within-and between-scorer estimates were close. For both methods, there was clear indication that scores for females were more repeatable. Similar results were observed for younger animals and also for the better-conditioned animals. In the weighbridge, repeatabilities of scores of animals that had crossbred dams were much lower than those that had zebu dams or the purebred zebu animals. However, in the crush, scores for the zebu animals were less repeatable.

\section{DISCUSSION}

In this study, scorer and animal $\mathrm{x}$ scorer variations were negligible, indicating that the scorers did not differ much in their implied calibration of the scoring scale or in their interpretation of the subjective criterion. Evans (1978), in a similar study on condition scoring, found these variations to be significant and concluded that scorers need to be carefully trained. The between-animal variation in the weighbridge was almost twice that in the cattle crush, possibly because there was more freedom for movement for animals in the weighbridge. Exhibition of temperament was therefore more enhanced. Repeatability of scorers between scorers was moderate for method 1 and somewhat lower for method 2. A very high significant correiation (0.94) between scorers was obtained by Fordyce et al. (1985). However, in their study, both observers were experienced stock handlers and had practised scoring before the experiment. Here, the scorers were still unfamiliar with the procedure since it was their first time of scoring. Hearnshaw and Morris (1984) also obtained a low repeatability of 0.27 from inexperienced scorers. It appears that there is more reliability in scoring of female, older and better-conditioned animals. A similar observation on effect of age was made by Hearnshaw and Morris (1984) who reported repeatability of 0.67 for calves and 0.82 for cows. Fordyce and Goddard (1984) found repeatabilities of $0.28-0.52$ for five of six measures of temperament in cows.

In conclusion, the rcsults of this study show that scoring animals for temperament in an enclosure where the animals can be sevarated singly and scored (Weighbridge) is more reliable than scoring in cattle crushes. Jnder such situations, temperament is better expressed. Even though the repeatability estimates obtained were low to moderate, with more practice in scoring, the reliability can be improved. Temperament scoring could then be used as an effective management tool on farms particularly in the tropics where there is a predominance of temperamental cattle. 


\section{ACKNOWLEDGEMENT}

The authors acknowledge with gratitude the technical assistance of Tanimu Waziri and Shehu Haruna. The kind permission of the Director to publish this work is also acknowledged.

\section{REFERENCES}

ABUBAKAR, B. Y., ONI, O. O. and MALAU-ADULI, A. E. O. (1991). Factors affecting temperament in Bunaji and Friesian-Bunaji crossbren cattle. Nig. J. of Anim. Prod., 18: 66-69.

BUVANENDRAN, V., OLAYIWOLE, M.B. and PIOTROWSKA, K. O. J. (1981). A comparison of milk production traits in Friesian $\mathrm{x}$ White Fulani crosses. Animal Production 32: $165-170$.

CZAKO, K. (1979). The effect of animal behaviour on the technical design of the milking process. Agrartechnik 29: 53-54.

ELDER, J. K., WATERS, K. S., DUNWELL, G. H., EMMERSON, F. R., KEARNAN, J. F., MORRIS, R. S. and KNOTT, S. G. (1980). A survey concerning cattle tick control in Queensland. 2. Management aspects which indirectly affect tick control. Australian Veterinary Journal, 56: 205-211.

EVANS, D. G. (1978). The interpretation and analysis of subjective body condition scores. Animal Production 26: 119-125.
FORDYCE, G., GODDARD, M. E. TYLER, R., WILLIAMS, G. and TOLEMON, M. A. (1985). Temperament and bruising of Bos indicus cross cattle. Australian Journal of Experimental Agriculture, 25: $283-288$.

HEARNSHAW, H., BARLOW, R. and WANT, G. (1979). Development of a temperament or handling difficulty score for cattle. Proceedings of the Australian Association of Animal Breeding and Genetics, 1: 164-166.

HEARNSHAW, G. and MORRIS, C. A. (1984). Genetic and environmental effects on a temperament score in beef cattle. Australian Journal of Agricultural Research, 35: 723-733.

HENDERSON, C. R. (1959). Design and analysis of animal husbandry experiments. In: Techniques and procedures in Animal Production Research. pp. 35. American Society of Animal Production Champaign, Illinois.

HOLMES, J. H. G., ROBINSON, D. W. and ASHMORE, G. R. (1972). Blood lactic acid and behaviour in cattle with hereditary muscular dystrophy. Journal of Animal Science, 35: 1011-1013.

PULAN, N. B. (1978). Condition scoring of White Fulani cattle. Tropical Animal Health and Production, 10: 119-120.

SEARLE, S. R. (1971). Linear Models. Wiley, New York.

TULLOH, N. H. (1961). Behaviour of cattle in yards. II. A study of temperament. Animal Behaviour, 9: 25-30. 